1 O'Connor, R. J., Boaden, P. J. S., and Seed, R., Nature, 256, 307-309 (1975)

Siegel, S., Nomparametric Statistics for the Behavioral Sciences (McGraw-Hill, London, 1956).

3 Cody, M. L., Competition and the Structure of Bird Communities (Princeton University Press, Princeton, 1974).

4 Levins, R., Evolution in Changing Environments (Princeton University Press, Princeton, 1968).

O'CONNOR ET AL. REPLY-Crozier and Day $^{1}$ offer four distinct criticisms of our analysis ${ }^{2}$ of niche breadth in Bryozoa. They suggest, first, that on fronds which are more suitable overall some of the less favoured segments would become acceptable, yielding a competition-free correlation between range and population level. As we pointed out explicitly in our paper, however, the available space at the optimum height is not physically filled at the higher population levels, so that animals settling elsewhere are behaving maladaptively if intraspecific competition is absent. Competition theory readily explains such suboptimal settlement in terms of a balance between the disadvantages of being away from the competition-free optimum of the resource gradient and the advantages of the reduced intraspecific competition found away from the optimum ${ }^{3,4}$; the model suggested by Crozier and Day $^{1}$ leaves us, on the other hand, with unexplained maladaptive behaviour on the part of the bryozoans.

The linear dart target criticism advanced is essentially that of Harvey et $a l^{5}$, to which we have responded with a partial correlation analysis ${ }^{6} \mathrm{de}$ monstrating that increase in resource range with increasing Alcyonidium population size was independent of the number of observations or 'darts'. We note in addition here that the dart effect is in any case too small to account for our results. Thus, if the change in Alcyonidium numbers between $2 \%$ and $4 \%$ cover (the latter being our median value) involved an increase of as few as 2 individuals at settlement, the dart effect predicts ${ }^{7}$ only an increase in range of $84 \%$, whereas we empirically observed an increase of $178 \%$; for a slightly more realistic change of from 10 to 20 individuals, the dart effect is even less $(21.4 \%)$, increasing the shortfall from the observed change even further. Similar calculations over other ranges of population size confirm our original conclusion, since the observed range increases are always substantially larger than any possible effect of sample size.

The third criticism by Crozier and $D{ }^{1}{ }^{1}$, that the effect of sample size could explain our interspecific results, is incorrect on two grounds. First, for our interspecific analysis we used not the range of the resource utilisation function but rather its width at half height. This measure more closely resembles a standard deviation than a range in its statistical behaviour, that is, it is largely insensitive to changes in sample size. Second, even if this measure had been subject to the effect of sample size, the resulting increase would have been too small to account for the observed changes in niche breadth. Thus, for Alcyonidium our sample size effectively doubled (from 69 to 149) between the one-competitor and no-competitor situations: Fisher and Yates' table ${ }^{7}$ shows that the effect of such a doubling of sample size would have been less than $14 \%$, whereas the observed increase was of $34 \%$, substantially larger. Similar calculations for the other seven comparisons show that in six cases the dart effect is too small by even bigger factors to account for the observed increases: only for the change in Membranipora niche breadth between the one- and two-competitor situations could an effect of sample size have accounted for the observed change. Therefore, even after assuming we had used range, and not the more stable width at half height, as our measure of niche breadth, the effects of the differences in sample sizes are so small that after making full allowance for them, seven of the eight comparisons are still indicative of competitive effects (Sign test $\left.^{8}, P<0.05\right)$, that is, the data still demonstrate that the presence of interspecific competitors on fronds reduces bryozoan niche breadths on those fronds. We thus disregard this criticism of Crozier and Day'.

Their final criticism is that the analyses chosen by them failed to support our conclusions. We note first that they overstate their case with respect to the Kolmogorov-Smirnov test: Siegel ${ }^{8}$ explicitly states (p. 129) that the failure of this test to reject a null hypothesis (here that the one-competitor and no-competitor curves do not differ) does not mean that the hypothesis should then be accepted, contrary to the assertion of Crozier and Day. Second, we note that the formula

$$
\ln B=-\Sigma p_{\mathrm{i}} \ln p_{\mathrm{i}}
$$

requires that niche breadth be related to the Shannon-Wiener index of species diversity, $H$, by $B==\exp (H)$. Niche breadth and species diversity are thus mathematically related. Since we know from empirical evidence ${ }^{9}$ that different diversity indices lead to different biological conclusions, even when applied to the same data, we are unable to accept any one of the related niche breadth formulae as definitive. The widespread acceptance of any particular formula may merely reflect uncritical acceptance of its hidden assumptions. The measure of niche breadth we used has the merit of being distribution free and has an even more widespread acceptance in mea- suring distribution widths ${ }^{10}$ than the information theory measure tested by Crozicr and Day. We would naturally like to see all niche breadth measures tested with our data supporting our conclusions, but when simple measures support biologically sensible conclusions and complex measures fail to do so, we feel it appropriate to suggest that maybe the mathematics, rather than the biology, is at fault.

In summary, therefore, the criticisms offered by Crozier and Day ${ }^{1}$ are only partially valid, and have too small an effect to invalidate our conclusions.

We thank Jim Gilliam for helpful discussion.

University College of North Wales and The Queen's University of Belfast, UK

\footnotetext{
1 Crozier, !R. H., and Day, R. W., Nature, 260, 77

O'Connor. R. J., Boaden, P. J. S., and Seed, R., Nature, 256, 307-309 (1975)

MacArthur, R. H., Geographical Ecology (Harper and Row, New York, 1972).

Pianka, E. R., Evolutionary Ecology (Harper and Row, New York, 1974)

Harvey, P. H., Ryland, J. S., and Hayward, P. J., Nature, 260, 77 (1976).

O'Connor, R. J., Boaden, P. J. S., and Seed, R., Nature, 260, 77 (1976).

Fisher, R. A., and Yates, F., Statistical Tables for Biological, Agricultural and Medical Research (Oliver and Boyd, London, 1963)

8 Siegel, S., Nomparametric Statistics for the Behavioral Sciences (McGraw-Hill, New York, 1956).

9 Room, P. M., Aust. J. Zool., 23, 71-89 (1975). Eisberg, R. M. Fundamentals
(Wiley, New York, 1961).
}

\section{Enteropancreatic circulation of digestive enzyme}

WE are studying highly specific intracellular proteinases and have read with interest yet alarm the two recent reports ${ }^{1,2}$ by Rothman et al. proposing an enteropancreatic circulation for digestive enzymes. This seems unlikely for the following reasons (accepting the premise that protein molecules can be transported across intestinal and pancreatic acinar cells).

If the proteins are absorbed into the bloodstream in the active enzyme forms (chymotrypsin and trypsin, for example) they would be inactivated very rapidly by the plasma inhibitors such as $\alpha_{1}$-antitrypsin, $\alpha_{1}$-antichymotrypsin and $\alpha_{m-m a c r o g l o b u l i n}$ hefore they could hydrolyse physiological substrates like prothrombin, fibrinogen, plasminogen and kininogen. If any active molecules were lucky enough to escape this bombardment by circulating inhibitors and be reabsorbed by the pancreas, what a cruel fate to be inactivated at the last hurdle by the pancreatic inhibitors.

If the proteins are absorbed in the non-activated forms of chymotrypsinogen and trypsinogen, they might iust- escape the attention of the inhibitors and be reabsorbed by the pancreas 